\title{
Nephrotoxicity, high frequency ototoxicity, efficacy and serum kinetics of once versus thrice daily dosing of netilmicin in patients with serious infections
}

\author{
J. Blasere"*, H. P. Simmen, U. Thurnheer^, C. König* and R. Lüthy* \\ ${ }^{a}$ Department of Medicine, D POL 40, University Hospital Zurich, CH-8091 Zurich, \\ Switzerland; 'Anna Seiler Haus, Inselspital Berne, Berne, Switzerland
}

\begin{abstract}
The effect of dosing regimen on nephrotoxicity, high frequency ototoxicity, efficacy and serum kinetics was studied in a prospective, randomised clinical study. Therapy was started with total daily doses of $6 \mathrm{mg} / \mathrm{kg}$ given once (od) or thrice (tid) daily to 56 and 57 patients, respectively. Subsequent doses were adjusted according to serum levels. No major differences in toxicity or efficacy were noticed between od and tid regimens: clinical failures occurred in two and two patients, four and five patients suffered from a decrease of $\geq 20 \mathrm{~dB}$ at least unilaterally at one frequency between 8 and $18 \mathrm{kHz}$, six and seven patients had a $>25 \mu \mathrm{mol} / \mathrm{L}$ or $>25 \%$ increase in serum creatinine, respectively. Serum creatinine or creatinine clearance did not change significantly during either therapy. Major differences between the two study groups were limited to pharmacokinetic parameters. Od dosing resulted in higher peak (mean of 21.6 vs $7.2 \mathrm{mg} / \mathrm{L}$ ) and lower trough levels $(0.5$ vs $1.4 \mathrm{mg} / \mathrm{L})$. Half-lives of netilmicin determined between 1 and $8 \mathrm{~h}$ increased significantly during therapy with tid (from a mean of 2.75 to a mean of $3.33 \mathrm{~h}, P<0.01$ ) but not significantly with od (rise from 2.8 to $3.03 \mathrm{~h}$ ). Much longer half-lives were determined between 8 and $24 \mathrm{~h}$ in the od group (mean of $5.7 \mathrm{~h}, P<0.01$ ). In conclusion, only minimal differences in toxicity and efficacy were observed. Their clinical relevance appears to be minimal.
\end{abstract}

\section{Introduction}

For several decades aminoglycoside antibiotics have been administered as multiple daily dosing regimens. An increasing number of experimental and clinical studies nowadays suggests that once daily dosing regimens (od) might be at least as efficacious and not more or possibly even less toxic (Bennett et al., 1979; Powell et al., 1983; Craig, Redington \& Ebert, 1991; Gilbert, 1991; Prins et al., 1993; EORTC, 1993).

This clinical trial compared single versus thrice daily (tid) administration of netilmicin in seriously ill patients. Pharmacokinetics, nephrotoxicity, high frequency ototoxicity, clinical and bacteriological efficacy were considered in a prospective, randomised, open trial performed in two Swiss Hospitals.

*Tel: +41-(1)-2553618; Fax: +41-(1)-2554562. 


\section{Patients \& methods}

\section{Patients}

Patients aged $\geq 16$ years with suspected or verified bacterial infections serious enough to require aminoglycoside therapy were eligible. Informed consent was obtained. Exclusion criteria were: (1) known allergy to aminoglycosides, (2) pregnancy, (3) treatment with an aminoglycoside within the preceding 4 weeks, (4) previous enrolment in the study, (5) renal impairment (initial serum creatinine $>130 \mu \mathrm{mol} / \mathrm{L}$ ) and (6) known reduced auditory function. 94 patients were treated in the Departments of Medicine and Surgery at the University Hospital in Zurich, 19 patients were treated at the Anna Seiler Haus, Inselspital, Berne, Switzerland.

\section{Antibiotic therapy}

All patients (except one tid-treated patient) received netilmicin in combination with at least one other antibiotic (Table I). Patients were randomised in a prospective study to receive initial daily doses of netilmicin of $6 \mathrm{mg} / \mathrm{kg}$ either as a single daily dose or as three divided doses. Netilmicin was given as an intravenous infusion over $60 \mathrm{~min}$. Serum samples of netilmicin were collected during the second day of treatment and thereafter every two to three days. Samples were obtained immediately at the end of the $1 \mathrm{~h}$-infusion, $8 \mathrm{~h}$ after the onset of the infusion and also after $24 \mathrm{~h}$ for the od regimens. Doses were adjusted whenever $8 \mathrm{~h}$ levels were outside the target range of $1.5-6 \mathrm{mg} / \mathrm{L}$ and $0.5-2 \mathrm{mg} / \mathrm{L}$ for od and tid regimens, respectively (Blaser et al., 1994). Peak levels of $18-24 \mathrm{mg} / \mathrm{L}$ and 6-8 $\mathrm{mg} / \mathrm{L}$ were considered optimal for od and tid regimens, respectively.

\section{Netilmicin assay}

Netilmicin serum concentrations were measured by fluorescence polarisation assay (TDx, Abbott Laboratories). The coefficient of variation of the assay was $<10 \%$ for concentrations of $>1 \mathrm{mg} / \mathrm{L}$ (Joos, Lüthy \& Blaser, 1989). Spiked specimens of $0.5,0.25$ and $0 \mathrm{mg} / \mathrm{L}$ were measured as $0.52 \pm 0.03,0.31 \pm 0.04$ and $0.07 \pm 0.06 \mathrm{mg} / \mathrm{L}$ (mean \pm standard deviation), respectively.

\section{Evaluation of nephrotoxicity}

An initial serum creatinine was measured before or at onset of therapy, every second or third day during therapy and finally on day one or two after cessation of therapy. In addition, $24 \mathrm{~h}$-creatinine-clearance was also determined when possible, both at the beginning of therapy and also one or two days after completion of therapy. Urine was collected over a $24 \mathrm{~h}$ period and serum creatinine measured within this period. Nephrotoxicity was defined as an increase of the final serum creatinine of $>25 \mu \mathrm{mol} / \mathrm{L}$ or $25 \%$ above the initial value or a decrease in creatinine clearance of $>25 \mathrm{~mL} / \mathrm{min}$ or $25 \%$ below the initial measurement (Blaser et al., 1994). Threshold values applied by other investigators to define nephrotoxicity reach from a serum creatinine increase of $>15 \%$ to $\geq 50 \%$ (Nordstrōm et al., 1990; de Vries et al., 1990). 


\section{Evaluation of auditory toxicity}

Auditory function was monitored where possible during treatment by high frequency audiometry (Interacoustics High Frequency Audiometer Model AS $10 \mathrm{HF}$ ) at 8, 10, 12, 14,16 and $18 \mathrm{kHz}$. The audiometry was performed at the bedside with alert patients only. Some patients, however, were too ill to allow for a reliable audiometry. Any disturbing noises were avoided within the room while audiometry was carried out. Change of auditory function during therapy was determined as a difference between the initial and final assessment of the auditory thresholds. Auditory toxicity was defined as an increase of $\geq 20 \mathrm{~dB}$ in auditory threshold at least unilaterally at one frequency.

The quality of the audiometry tests was assessed in a control study in which 13 healthy volunteers were enrolled, to document the variability of the measurement of the hearing threshold not induced by the administration of any ototoxic compounds. Four audiometries were performed per volunteer within a month, two in a quiet room and another two with distracting background noises (an audio tape with a comedy show, including a lot of laughter).

\section{Microbiology}

Samples of blood, sputum, abscess material, drainage fluids or urine were taken before start of netilmicin treatment and, where feasible, during and after completion of therapy. Identification of pathogens and susceptibility testing according to standard techniques was done at the Institutes for Medical Microbiology of the Universities of Zurich and Berne.

\section{Evaluation of clinical and bacteriological response}

A patient's clinical response was considered satisfactory if (1) clinical signs or symptoms of infection resolved or improved or (2) the bacterial pathogens, whenever isolated, were eradicated. In contrast, a patient's course was considered unsatisfactory if (1) clinical signs or symptoms of the infection persisted or deteriorated, (2) a relapse occurred after initial improvement or (3) the patient died due to infection. A patient's course was classified indeterminate if (1) an initially presumed bacterial infection was ruled out during follow-up, (2) an infection was caused by a pathogen resistant to netilmicin already at start of treatment or if (3) there was a serious non-infectious underlying disease which did not allow for a clinical evaluation of the effect of the antibiotic therapy. The bacteriological response was classified as elimination, when follow-up cultures remained sterile, persistence or relapse, when the cultures remained positive for the same organisms or when these organisms were cultured again after discontinuation of treatment, respectively. When specimens for follow-up cultures were not available because of clinical cure, bacteriological response was classified as indeterminate.

\section{Statistical analysis}

The volume of distribution was calculated as the ratio between administered dose and the difference between peak and trough concentrations. Half-lives were calculated according to an exponential decline between two concentrations. For comparison of the two groups the Mann-Whitney $U$ test and the contingency test were used for analysis of 
Table I. Antibiotic combinations including netilmicin

\begin{tabular}{lrrr}
\hline $\begin{array}{l}\text { Netilmicin } \\
\text { in }\end{array}$ & od & tid & $P^{\circ}$ \\
\hline $\begin{array}{l}\text { Dual combination with } \\
\text { penicillin }\end{array}$ & 30 & 32 & 0.72 \\
$\quad \begin{aligned} \text { cephalosporin } \\
\text { various }\end{aligned}$ & 8 & 2 & 0.11 \\
$\begin{array}{l}\text { Triple combination with } \\
\quad \text { penicillin + imidazole }\end{array}$ & 13 & 1 & 0.63 \\
$\quad$ penicillin + various & 13 & 19 & 0.26 \\
$\quad$ cephalosporin + various & 3 & 2 & 0.97 \\
Total combinations & 5 & 4 & 0.96 \\
\hline
\end{tabular}

•Contingency table with continuity correction.

continuous or categorical variables, respectively. Changes in clinical parameters during therapy within one treatment group were analysed by the Wilcoxon signed rank test. All statistical calculations were performed with the program StatViewII, Abacus Concepts, Berkeley, California. All significance probabilities were calculated for the two-tailed tests.

\section{Results}

\section{Patients}

A total of 113 patients, 56 od-treated patients and 57 tid-treated patients, were randomised. The two treatment groups were comparable with respect to sex, age, weight, temperature and arterial pressure (Table II). One third of all patients had abdominal infections (Table III). The distribution of infection sites did not differ statistically between both groups. The groups were also comparable with respect to the bacterial pathogens. Gram-positive and -negative organisms were found at similar frequencies in patients from which a single pathogen could be isolated (Table IV). All patients except one tid-treated patient received netilmicin in combination with at least one other antibiotic (Table I). In 16 of 17 combinations included cephalosporins, either ceftriaxone or ceftazidime, while one patient received two first generation cephalosporins, cefoxitin and cephradine, consecutively. In each treatment group netilmicin was administered in combination with vancomycin in three patients. In both groups, two of these three patients received a

Table II. Baseline clinical characteristics

\begin{tabular}{|c|c|c|c|}
\hline Evaluable patients & $\begin{array}{l}\text { od } \\
56\end{array}$ & $\begin{array}{l}\text { tid } \\
57\end{array}$ & $P$ \\
\hline Male/female & $44 / 12$ & $37 / 20$ & $0.16^{b}$ \\
\hline Age (year) & $48(19-82)$ & $48(17-84)$ & $0.40^{\circ}$ \\
\hline Temperature $\left({ }^{\circ} \mathrm{C}\right)^{\alpha}$ & $38.3(36.4-40.6)$ & $38.4(36.2-41.0)$ & $0.37^{\mathrm{c}}$ \\
\hline Arterial pressure $(\mathrm{mmHg})^{a}$ & $120 / 70$ & $120 / 70$ & $0.98^{c}$ \\
\hline Weight $(\mathrm{kg})^{\prime}$ & $69(47-110)$ & $65(40-111)$ & $0.08^{\mathrm{c}}$ \\
\hline
\end{tabular}

Median (range).

Contingency table with continuity correction.

'Mann-Whitney U test. 
Table III. Primary infection site

\begin{tabular}{lrrc}
\hline & od & tid & $P$ \\
\hline Abdomen & 18 & 21 & 0.74 \\
Uro-genital tract & 8 & 2 & 0.09 \\
Respiratory tract & 6 & 10 & 0.44 \\
Endocarditis & 10 & 5 & 0.25 \\
Bacteraemia & 5 & 2 & 0.42 \\
Unexplained fever & 4 & 13 & 0.04 \\
Various & 5 & 4 & 0.98 \\
Total & 56 & 57 & \\
\hline
\end{tabular}

"Contingency table with continuity correction.

${ }^{b}$ Patients in aplasia after chemotherapy for leukaemia, non-Hodgkin-lymphoma or other tumours.

cephalosporin as a third antibiotic. Thirteen and ten patients also received a furosemide in the od- and tid-treatment group, respectively. No statistically significant differences were observed between the treatment groups with respect to combinations with other antibiotics or with furosemide.

\section{Dosing and serum kinetics of netilmicin}

Initial daily doses of netilmicin were not significantly different for the two groups (Table V). On an average the mean daily dose was reduced during therapy by $5.7 \%$ for od and $10.3 \%(P<0.05)$ for tid. Median (and range) of the initial and final dose during od-dosing were $400 \mathrm{mg}(280-500)$ and $400 \mathrm{mg}(130-600)$ and during tid-dosing $360 \mathrm{mg}$ (210-600) and $360 \mathrm{mg}(150-600)$, respectively. Thereby, the final daily dose of the tid-regimen was significantly lower than that of the od-regimen. No statistical differences between the two treatment groups were observed with respect to the cumulative dose or

Table IV. Microbiology

\begin{tabular}{lrrc}
\hline & od & tid & $P^{a}$ \\
\hline Single pathogen & 21 & 14 & 0.20 \\
$\quad$ Staphylococcus aureus & 4 & 5 & \\
Coagulase-negative & & & \\
Staphylococci & 2 & 0 & \\
Streptococci & 3 & 0 & \\
Escherichia coli & 3 & 3 & \\
Pseudomonas aeruginosa & 2 & 4 & \\
Other & 7 & 2 & \\
Polymicrobial & 15 & 14 & 0.96 \\
$\quad$ with anaerobes & 9 & 6 & \\
without anaerobes & 6 & 8 & \\
No growth & 20 & 29 & 0.15 \\
Total & 56 & 57 & \\
\hline
\end{tabular}

¿Contingency table with continuity correction. 
Table V. Treatment characteristics

\begin{tabular}{lccc}
\hline Evaluable patients & od & tid & \\
& 56 & 57 & $P^{a}$ \\
\hline Total daily dose (mg) & & & \\
initial & $406( \pm 66)^{b}$ & $379( \pm 83)$ & 0.07 \\
final & $383( \pm 104)$ & $340( \pm 98)^{c}$ & 0.02 \\
Total cumulative dose (mg) & $3178( \pm 1836)$ & $3331( \pm 2245)$ & 0.92 \\
Duration of treatment (days) & $8.5( \pm 4.9)$ & $10( \pm 6.9)$ & 0.14 \\
\hline 'Mann-Whitney U test. & & & \\
'Mean ( \pm S.D.) & & & \\
'Significant differences between initial and final values withrn one treatment group as \\
calculated by Wilcoxon signed-rank test, $P<0.05$.
\end{tabular}

the duration of therapy. Median duration (range) of od and tid treatment were 7 days (3-25) and 8 days (3-39), respectively.

Three-fold higher peak levels of netilmicin were obtained with the od regimen (Table VI). Also $8 \mathrm{~h}$ levels were significantly higher during od dosing. On an average the $24 \mathrm{~h}$ troughs during od treatment were still $39 \%$ of the $8 \mathrm{~h}$ troughs observed during tid dosing. For both regimens only the trough levels increased significantly during therapy. Volumes of distribution were similar in both study groups as well as the half-lives observed between $1 \mathrm{~h}$ and $8 \mathrm{~h}$. During tid therapy mean half-lives increased significantly by $21 \%$, whereas no significant increase $(8 \%)$ occurred with od therapy. Remarkably longer half-lives were determined within the 8 to $24 \mathrm{~h}$ period of the od regimen. On an average these half-lives were $93 \%$ longer compared to those observed within the first $8 \mathrm{~h}$ of the $24 \mathrm{~h}$ dosing interval $(P<0.001)$, (Table VII).

\section{Toxicity}

Changes between the initial and final serum creatinine concentrations were determined in 112 of the 113 patients enrolled (Table VIII). The patients in the tid group had lower serum creatinine levels at the onset of therapy whereas no significant differences were

Table VI. Serum levels of netilmicin

\begin{tabular}{|c|c|c|c|c|}
\hline \multicolumn{2}{|c|}{ Evaluable patients } & $\begin{array}{l}\text { od } \\
42\end{array}$ & $\begin{array}{l}\text { tid } \\
53\end{array}$ & $P$ \\
\hline \multicolumn{5}{|c|}{ Serum levels (mg/L) } \\
\hline peak & $\begin{array}{l}\text { initial } \\
\text { final }\end{array}$ & $\begin{array}{l}22.1( \pm 7.0)^{b} \\
21.1( \pm 6.2)\end{array}$ & $\begin{array}{l}7.35( \pm 2.70) \\
7.04( \pm 1.91)\end{array}$ & $\begin{array}{l}<0.001 \\
<0.001\end{array}$ \\
\hline \multirow[t]{2}{*}{ 8-h level } & initial & $3.58( \pm 2.35)$ & $1.23( \pm 0.83)$ & $<0.001$ \\
\hline & final & $3.68( \pm 1.47)$ & $1.48( \pm 0.73)^{r}$ & $<0.001$ \\
\hline \multirow[t]{2}{*}{ 24-h level } & initial & $0.46( \pm 0.51)$ & & \\
\hline & final & $0.60( \pm 0.77)^{c}$ & & \\
\hline
\end{tabular}


Table VII. Serum kinetics of netilmicin

\begin{tabular}{|c|c|c|c|c|}
\hline Evaluable patients & & $\begin{array}{l}\text { od } \\
42\end{array}$ & $\begin{array}{l}\text { tid } \\
53\end{array}$ & $P^{\infty}$ \\
\hline \multicolumn{5}{|c|}{ Volumes of distribution (L) } \\
\hline & $\begin{array}{l}\text { initial } \\
\text { final }\end{array}$ & $\begin{array}{l}20.4( \pm 6.4)^{6} \\
19.8( \pm 6.0)\end{array}$ & $\begin{array}{l}23.3( \pm 10.2) \\
21.8( \pm 7.2)\end{array}$ & $\begin{array}{l}0.26 \\
0.26\end{array}$ \\
\hline \multicolumn{5}{|l|}{ Half-lives (h) } \\
\hline \multirow[t]{2}{*}{ between 1 and 8} & initial & $2.84( \pm 1.17)$ & $2.75( \pm 0.86)$ & 0.96 \\
\hline & final & $3.03( \pm 1.33)$ & $3.33( \pm 1.26)^{c}$ & 0.17 \\
\hline \multirow[t]{2}{*}{ between 8 and 24} & initial & $5.29( \pm 1.33)$ & & \\
\hline & final & $6.04( \pm 3.56)$ & & \\
\hline \multirow[t]{2}{*}{ between 1 and 24} & initial & $3.96( \pm 0.91)$ & & \\
\hline & final & $4.57( \pm 2.29)^{c}$ & & \\
\hline
\end{tabular}

'Mann-Whitney U-test.

"Mean ( \pm S.D.).

Significant difference between initial and final values within one treatment group as calculated by Wilcoxon signed-rank test; $P<0.05$.

present at the end of therapy. Also, no significant changes of serum creatinine were observed between initial and final values within each study group. However, a total of 13 patients, six and seven patients in the od and tid treatment group, respectively, experienced an increase of serum creatinine of $>25 \%$ or $25 \mu \mathrm{mol} / \mathrm{L}$. In each group, one of these patients received frusemide. Netilmicin was combined with a penicillin in ten of these 13 patients. A serum creatinine increase of $>100 \%$ was documented in two patients in either treatment group. Three of these received netilmicin plus a penicillin, the fourth received a combination of netilmicin, amoxycillin, imidazole and frusemide.

Initial and final $24 \mathrm{~h}$ creatinine clearance data were available for 30 od-and 27 tid-treated patients only (Table IX). No significant changes in clearance occurred during treatment within each study group. Also, no significant differences of the clearance rates were present between both groups at the onset or at the end of treatment. However, $37 \%$

Table VIII. Serum creatinine

\begin{tabular}{lccc}
\hline Evaluable patients & $\begin{array}{c}\text { od } \\
55\end{array}$ & $\begin{array}{c}\text { tid } \\
57\end{array}$ & $P$ \\
\hline $\begin{array}{l}\text { Serum creatinine }(\mu \mathrm{mol} / \mathrm{L}) \\
\text { initial } \\
\text { final }\end{array}$ & $97(52-133)$ & $87(50-118)$ & $0.03^{b}$ \\
$\begin{array}{l}\text { Change of serum creatinine } \\
\text { during therapy } \\
\text { number of patients with an increase } \\
525 \%\end{array}$ & $94(47-410)$ & $85(60-203)$ & $0.22^{b}$ \\
$>25 \%$ & & & \\
\hline $\begin{array}{l}\text { 'Median (range). } \\
\text { "Mann-Whitney U test. } \\
\text { c' Contingency table with continuity correction. }\end{array}$ & 69 & 50 & $0.95^{c}$ \\
\hline
\end{tabular}


Table IX. Creatinine clearance

\begin{tabular}{|c|c|c|c|}
\hline Evaluable patients & $\begin{array}{l}\text { od } \\
30\end{array}$ & $\begin{array}{l}\text { tid } \\
27\end{array}$ & $P$ \\
\hline \multicolumn{4}{|c|}{ Creatinine clearance $(\mathrm{mL} / \mathrm{min})$} \\
\hline initial & $92(21-216)^{a}$ & $83(31-177)$ & $0.88^{b}$ \\
\hline final & $95(20-183)$ & $83(32-144)$ & $0.56^{b}$ \\
\hline \multicolumn{4}{|c|}{$\begin{array}{l}\text { Change of creatinine clearance } \\
\text { during therapy }\end{array}$} \\
\hline \multicolumn{4}{|c|}{$\begin{array}{l}\text { ourning therapy } \\
\text { number of patients with an decrease }\end{array}$} \\
\hline$\leq 25 \%$ & 19 & 20 & \\
\hline$>25 \%$ & 11 & 7 & $0.56^{\circ}$ \\
\hline
\end{tabular}

and $26 \%$ of od and tid treated patients, respectively, experienced a decrease of creatinine clearance of $>25 \%(P=0.56)$.

Initial and final audiometric data were available for 38 od and 47 tid patients (Table X). In each group $11 \%$ of the patients monitored suffered from a hearing loss $\geq 20 \mathrm{~dB}$ at least unilaterally, at one frequency. A total of 336 and 441 threshold differences of initial and final audiometries were analysed for the od and tid treated patients, respectively. The median changes in auditory function was $0 \mathrm{~dB}$ in both groups. There was, however, a statistically but not clinically significant difference in the mean changes, since auditory function improved by 0.3 and $1.7 \mathrm{~dB}$ for od and tid regimen, respectively. None of the patients in either group experienced a hearing loss at any frequency of $>25 \mathrm{~dB}$. Control audiometries with healthy volunteers documented that $91 \%$ of 468 differences in the hearing threshold between a baseline audiometry and a second assessment with or without distracting noises were within the range of +10 and $-10 \mathrm{~dB}$. In less than $2 \%$ a difference of $\geq 20 \mathrm{~dB}$ was observed in the volunteers, compared to $11 \%$ in the patients.

Table X. High frequency audiometry*

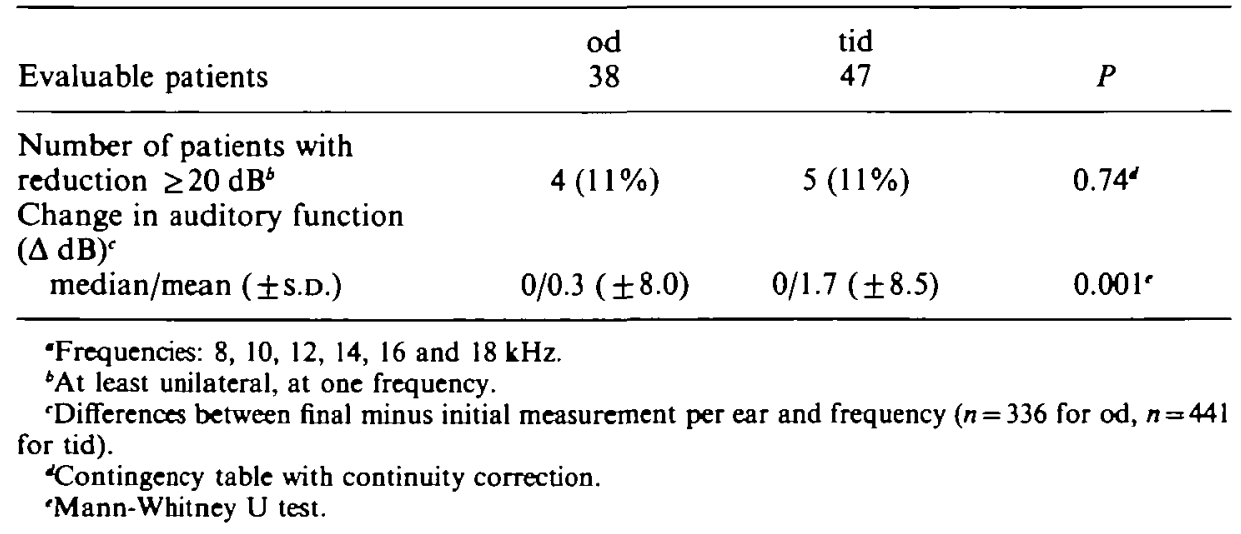


Table XI. Clinical and bacteriological outcome

\begin{tabular}{lrrr}
\hline & od & tid & \\
& 56 & 57 & $P$ \\
\hline Clinical outcome & & & \\
$\quad$ satisfactory & 41 & 36 & \\
$\quad$ unsatisfactory & 2 & 2 & 0.70 \\
indeterminate & 13 & 19 & \\
Bacteriological outcome & & & \\
$\quad$ with growth & 36 & 28 & \\
$\quad$ elimination & 11 & 11 & \\
$\quad$ persistence/relapse & $3 / 1$ & $5 / 0$ & 0.91 \\
$\quad$ indeterminate & 21 & 12 & \\
no growth & 20 & 29 & \\
\hline
\end{tabular}

“Contingency table with continuity correction.

\section{Evaluation of clinical and bacteriological response}

Clinical response to therapy could be evaluated in 43 of the 56 od and 38 of the 57 tid patients (Table XI). In each netilmicin treatment group two treatments were classified as unsatisfactory. Abdominal surgery has been performed before antibiotic treatment in all four patients where netilmicin therapy failed. Both od treated patients as well as one tid treated patient required a second operation despite administration of combination treatment with antibiotics to which the pathogens were sensitive in vitro. Persistence of the pathogens could be documented in two patients and a relapse in the third patient. In another tid treated patient the netilmicin susceptible pathogens causing the intraabdominal infection were never eradicated over a two week period of treatment and the patient died. Persistence of pathogens was documented for two further od-treated patients, one patient with a clinical outcome which could not be evaluated, the other with a satisfactory clinical response. Persistence of pathogens was also documented for three further tid-treated patients, where the clinical outcome could not be evaluated.

Six patients in the od group and five patients in the tid group died, including the above mentioned tid-treated patient where the pathogen persisted. All deaths but one were considered to be from underlying diseases, i.e. not caused by clinical failure or by adverse effects of the antibiotic therapy.

\section{Discussion}

In this prospective, randomised study no or only minor differences in toxicity and efficacy were noticed between od and tid regimens. The clinical relevance of the observed differences appears to be minimal. Major differences between the two study groups were limited to pharmacokinetic parameters. It was no surprise to find approximately three times higher peak concentrations and lower trough levels during once daily dosing. Half-lives of netilmicin determined between $1 \mathrm{~h}$ and $8 \mathrm{~h}$ increased during therapy with tid doses from a mean of 2.75 to a mean of $3.33 \mathrm{~h}(P<0.01)$ whereas no significant increase occurred with od (rise from 2.84 to $3.03 \mathrm{~h}$ ). Remarkably long half-lives were determined between $8 \mathrm{~h}$ and $24 \mathrm{~h}$ in the od group (mean of $5.7 \mathrm{~h}, P<0.01$ ). This relatively slow decline of serum concentrations might relate to the onset of the gamma-elimination-phase. Aminoglycosides accumulate in deep compartments, e.g. in the kidney, and are 
released from these compartments at a slow rate over prolonged periods (Schentag et al., 1977; Wenk, Vozeh \& Follath, 1984).

Most in-vitro and in-vivo studies have suggested that once daily dosing of aminoglycosides might result in better clinical efficacy or lower toxicity. Nevertheless, a few animal studies have shown superior efficacy with multiple daily dosing (Kapusnik et al., 1988; Fantin \& Carbon, 1990), possibly due to the very short half-lives of aminoglycosides in small animals (Gerber et al., 1986; Vogelman et al., 1988; Potel et al., 1991) resulting in prolonged periods of subinhibitory concentrations. In contrast, low serum concentrations were present in patients during od treatment only for limited time periods. The average half-life calculated from peak and trough levels during the $24 \mathrm{~h}$ dosing intervals was more than $4 \mathrm{~h}$.

Higher peak and lower trough levels have been achieved with the od regimen compared to thrice daily dosing. The need for higher peaks has been advocated because of concentration-dependent bacterial killing by aminoglycosides and the correlation of therapeutic outcome with the ratio of peak concentration to susceptibility of the pathogen (Blaser et al., 1987; Moore, Lietman \& Smith, 1987). A prolonged period of subinhibitory aminoglycoside concentrations might be acceptable for combined treatment with a $\beta$-lactam antibiotic and also because of the presence of a postantibiotic effect after exposure to high aminoglycoside concentrations (Vogelman et al., 1988). Concern about toxicity induced by high serum concentrations of a od aminoglycoside regimen has restricted its clinical use. However, the prolonged period with relatively low serum concentrations towards the end of the $24 \mathrm{~h}$ dosing interval may greatly reduce the danger of drug accumulation, thereby reducing the risk of ototoxic and nephrotoxic reactions (Gilbert, 1991).

This study and previously published clinical trials have not yet shown convincingly either better efficacy or lower toxicity with od dosing, except for one study demonstrating significantly lower nephrotoxicity of gentamicin (Prins et al., 1993). However, large numbers of patients are required to exclude a high risk for false-negative results. This is particularly true for the assessment of efficacy in heterogeneous study groups. Patients enrolled in most aminoglycoside dosing trials suffered from a great variety of different infections and pathogens as well as underlying diseases. Furthermore, clinical response is a consequence of combination therapy and, in many instances, surgical interventions. To assess in a quantitative and indisputable manner the contribution of od and tid aminoglycoside therapy for achieving bacteriological and clinical cure, a treatment group without any aminoglycoside therapy should be included, which might rise ethical concerns, and the randomisation procedure should stratify for various above mentioned factors, which would require for a study with patient numbers beyond the scope of most investigators.

Although no significant differences have been demonstrated in the present study between both parameters of toxicity and both parameters of efficacy, all four parameters studied were in favour of once daily dosing. In addition, once daily dosing is preferable from an economical point of view. Expanding the dosing interval reduces the risk of drug accumulation. Therefore, serum level monitoring becomes less important during od therapy of aminoglycosides and fewer blood specimens have to be processed (Blaser et al., 1994; Parker \& Davey, 1993). Thus, reducing the frequency of dosing to only once a day allows for considerable savings of both manpower and material. The data gathered in this study suggest that such saving would not be against the interest of the patients. 


\section{Acknowledgements}

We thank Mrs Margarete Alund, RN, for her excellent assistance in the organisation of the study. The study was supported in part by grants no. 3.913.0.85 and no. 32-33921.92 of the Swiss National Research Foundation and a grant of Essex Chemie AG, Lucerne, Switzerland.

\section{References}

Bennett, W. M., Plamp, C. E., Gilbert, D. N., Parker, R. A. \& Porter, G. A. (1979). The influence of dosage regimen on experimental gentamicin nephrotoxicity: dissociation of peak serum levels from renal failure. Journal of Infectious Diseases 140, 576-80.

Blaser, J., König, C., Simmen, H. P. \& Thurnheer, U. (1994). Monitoring serum concentrations for once daily dosing regimens of netilmicin. Journal of Antimicrobial Chemotherapy 33, 341-8.

Blaser, J., Stone, B. B., Groner, M. C. \& Zinner, S. H. (1987). Comparative study with enoxacin and netilmicin in a pharmacodynamic model to determine importance of ratio of antibiotic peak concentration to MIC for bactericidal activity and emergence of resistance. Antimicrobial Agents and Chemotherapy 31, 1054-60.

Craig, W. A., Redington, J. \& Ebert, S. C. (1991). Pharmacodynamics of amikacin in vitro and in mouse thigh and lung infections. Journal of Antimicrobial Chemotherapy 27, Suppl. C, 29-40.

de Vries, P. J., Verkooyen, R. P., Leguit, P. \& Verbrugh, H. A. (1990). Prospective randomized study of once-daily versus thrice-daily netilmicin regimens in patients with intraabdominal infections. European Journal of Clinical Microbiology and Infectious Diseases 9, 161-8.

EORTC International Antimicrobial Therapy Cooperative Group of the European Organisation for Research and Treatment of Cancer. (1993). Efficacy and toxicity of single daily doses of amikacin and ceftriaxone in patients with cancer and granulocytopenia. Annals of Internal Medicine 119, 584-93.

Fantin, B. \& Carbon, C. (1990). Importance of the aminoglycoside dosing regimen in the penicillin-netilmicin combination for treatment of Enterococcus faecalis-induced experimental endocarditis. Antimicrobial Agents and Chemotherapy 34, 2387-91.

Gerber, A. U., Brugger, H. P., Feller, C., Stritzko, T. \& Stalder, B. (1986). Antibiotic therapy of infections due to Pseudomonas aeruginosa in normal and granulocytopenic mice: comparison of murine and human pharmacokinetics. Journal of Infectious Diseases 153, 90-7.

Gilbert, D. N. (1991). Once-daily aminoglycoside therapy. Antimicrobial Agents and Chemotherapy 35, 399-405.

Joos, B., Lüthy, R. \& Blaser, J. (1989). Long term accuracy of fluorescence polarisation immunoassays for gentamicin, tobramycin, netilmicin and vancomycin. Journal of Antimicrobial Chemotherapy 24, 797-803.

Kapusnik, J. E., Hackbarth, C. J., Chambers, H. F., Carpenter, T. \& Sande, M. A. (1988). Single, large, daily dosing versus intermittent dosing of tobramycin for treating experimental Pseudomonas pneumonia. Journal of Infectious Diseases 158, 7-12.

Moore, R. D., Lietman, P. \& Smith, C. R. (1987). Clinical response to aminoglycoside therapy: importance of the ratio of peak concentration to minimal inhibitory concentration. Journal of Infectious Diseases 155, 93-7.

Nordström, L., Ringberg, H., Cronberg, S., Tjernström, O. \& Walder, M. (1990). Does administration of an aminoglycoside in a single daily dose affect its efficacy and toxicity? Journal of Antimicrobial Chemotherapy 25, 159-73.

Parker, S. E. \& Davey, P. G. (1993). Practicalities of once-daily aminoglycoside dosing. Journal of Antimicrobial Chemotherapy 31, 4-8.

Potel, G., Caillon, J., Fantin, B., Raza, J., Le Gallou, F., Lepage, J. Y. et al. (1991). Impact of dosage schedule on the efficacy of gentamicin, tobramycin, or amikacin in an experimental model of Serratia marcescens endocarditis: in vitro-in vivo correlation. Antimicrobial Agents and Chemotherapy 35, 111-6.

Powell, S. H., Thomson, W. L., Luthe, M. A., Stern, R. C., Grossniklas, D. A., Bloxham, D. L. et al. (1983). Once-daily vs. continuous aminoglycoside dosing: efficacy and toxicity in animal and clinical studies of gentamicin, netilmicin, and tobramycin. Journal of Infectious Diseases 147, 918-32. 
Prins, J. M., Büller, H. B., Kuiper, E. J., Tange, R. A. \& Speelman, P. (1993). Once versus thrice daily gentamicin in patients with serious infections. Lancet 341, 335-9.

Schentag, J. J., Jusko, W. J., Plaut, M. E., Cumbo, T. J., Vance, J. W. \& Abrutyn, E. (1977). Tissue persistence of gentamicin in man. Journal of American Medical Association 238, 327-9.

Vogelman, B., Gudmundsson, S., Turnidge, J., Leggett, J. \& Craig, W. A. (1988). In vivo postantibiotic effect in a thigh infection in neutropenic mice. Journal of Infectious Diseases 157, 287-98.

Wenk, M., Vozeh, S. \& Follath, F. (1984). Serum level monitoring of antibacterial drugs. A review. Clinical Pharmacokinetics 9, 475-92.

(Received 22 November 1994; returned 16 February 1995; revised 12 April 1995; accepted 12 June 1995) 